\title{
Finite Element Analysis of Natural Rubber, Glass-epoxy and Glass-rubber-epoxy Composites
}

\author{
Sangamesh Rajole ${ }^{1 *}$, Shivashankar Hiremath ${ }^{2}$, Ravishankar K Shankaranarayana Bhat ${ }^{1}$, Satyabodh M Kulkarni² \\ ${ }^{1}$ Department of Metallurgical and Materials Engineering, National Institute of Technology Karnataka, Surathkal, Mangalore \\ 575025, India \\ ${ }^{2}$ Department of Mechanical Engineering, National Institute of Technology Karnataka, Surathkal, Mangalore 575025, India
}

Corresponding Author Email: rajolesangmesh@gmail.com

https://doi.org/10.18280/ama_a.560102

Received: 25 October 2018

Accepted: 12 February 2019

\section{Keywords:}

energy absorption, ballistic limit, modelling, high-velocity impact, sandwich

\begin{abstract}
The present article focuses on the study of ballistic performance of the polymer composite sandwich, consisting of natural rubber (NR), glass-epoxy composite (GEC) and glassrubber-epoxy composite (GREC) for different thicknesses $(4,7$ and $10 \mathrm{~mm})$. Finite Element (FE) analysis is carried out to predict the energy absorption, ballistic limit velocity, and failure damage modes of the target composite are explored under the impact of the conical nose projectile for different velocity $(180,220$ and $260 \mathrm{~m} / \mathrm{s})$.

The study revealed that significant influences on ballistic impact are thickness, interlayer, and sandwiching composite materials. The energy absorbance and ballistic limit of GEC laminate are increases with an increase in thickness. In the case of interlayer composite GREC ballistic limit is higher than NR and GEC with the change in impact velocity, whereas NR is marginally lower than the GREC laminate. Hence, NR or GRE laminated composites are dominating more in the analysis of impact application.

These observations are extended for the experimental validation purpose. Also, these polymer composite materials could be served in the defense sector for bullet-proofing and high impact applications.
\end{abstract}

\section{INTRODUCTION}

Polymer composites are widely used in the automotive, aerospace, marine, sports, and defense sector [1], especially in defense applications such as personal protection, combat helmets, and armored vehicles. Special/secret protections, generally based on polymer composites, which reinforced with high-performance fibers such as aramid fibers, carbon fibers, and glass fibers [2]. These are extensively analyzed and studied their behavior for high-velocity impact loading, to satisfy the safety requirements $[2,3]$. Also, these polymer composites have an advantage like high specific stiffness, high energy absorption, and the strength to weight ratio made suitable for bullet-proofing/protection over conventional metals and alloys.

Recently few authors have been involved in the ballisticimpact response study using polyethylene terephthalate [PET] and nylon fibers, kevlar/polyester, graphite/epoxy/kevlar hybrid, woven Kevlar, Kevlar/Epoxy composites [4-8]. These composites have good dynamic strength, high cost, and are not environment-friendly. Hence, nowadays the trend is looking towards, incorporating natural materials into synthetic materials. A natural material like rubber coated to synthetic or natural fabric. These materials are improving the performance of the composites by $60 \%$ [9].

Ballistic energy absorption depends on continuous matrix and fiber properties. In the ballistic event, composites may fail due to matrix cracking, fiber breakage, debonding of fibers/matrix, and delaminating [10]. The previous study noticed that the effect of rubber layer incorporation with ceramic gave good resilience bond and also improves the ballistic multiple hit capacity of armor bock [11]. Rubber is one of the capable materials can be utilized for ballistic impact application due to its higher tear resistance and toughness [12]. It is also environment-friendly, low density and low cost [13, 14].

In the present study, comparative analysis of glass-epoxy composite (GEC), natural rubber (NR), glass-rubber-epoxy sandwich composite (GREC) is modeled using FE simulation software. These sandwich composite thickness $(4,7$, and 10 $\mathrm{mm}$ ) are varied with different impact velocity. The energy absorbance, ballistic limit, and composite fracture behaviors performances are investigated for the above composites. Among all three composites, the GREC sandwiches show better results than the rest.

The paper is organized like, in section 2 modeling steps of the sandwich composites and properties of the materials are highlighted. Theoretical analysis of the ballistic impact is explained in section.3. Finally results of energy absorption, ballistic limit and comparison study of GE, NR and GRE composite are discussed in section 4 followed by a conclusion.

\section{MODELLING OF SANDWICH COMPOSITES}

The Finite Element analysis is carried out for evaluating the ballistic impact performance of the rubber and polymer composites. In computer-aided engineering (CAE) part module, the polymer composite plate of $100 * 100 * \mathrm{X} \mathrm{mm}$ $(\mathrm{X}=4,7,10 \mathrm{~mm})$ is built as a deformable solid element. The projectile/bullet is shaped as three-dimensional rigid solid elements. The GEC and GREC properties are defined in the 
CAE-Property Module, which is listed in Table 1. The projectile and composite target plates are assembled in theAssembly Module, and the laminate is constrained in all directions. The impactor is assigned with velocity, to mimic and perform the actual ballistic impact analysis as shown in Figure 1(a). Laminated polymer composite plates are meshed using SC8R elements, and the impacting bullet/projectile meshes with C3D10R elements. The complete meshed assembly is shown in Figure 1(b). The model uses different modules to extract the results.

The FE simulation is carried for Natural rubber (NR), glassepoxy (GEC), glass-rubber-epoxy (GREC), for three thicknesses $(4,7$ and $10 \mathrm{~mm})$ with dimension $(100 \mathrm{~mm} \times 100$ $\mathrm{mm})$ by varying the velocity $(180,220$ and $260 \mathrm{~m} / \mathrm{s})$ of the impactor.

Table 1. Material properties of NR and GE [15]

\begin{tabular}{ccc}
\hline Material/Properties & Glass-Epoxy & Natural Rubber \\
\hline Density $\left(\mathrm{kg} / \mathrm{m}^{3}\right)$ & 1783 & Neo and hookean \\
& & parameters \\
Modulus $(\mathrm{GPa})$ & $\mathrm{E} 11=2.7$, & $\mathrm{C}_{11}=\mu / 2, \mathrm{D}_{1}=2 / \mathrm{K}$ \\
& $\mathrm{E} 22=8.0$ & $\mathrm{C}_{11}=16.77 \mathrm{E} 9 \mathrm{~Pa}$ \\
Poisons ratio & 0.37 & $\mathrm{D}_{1}=1.2 \mathrm{E}-9 \mathrm{~Pa}$ \\
\hline
\end{tabular}
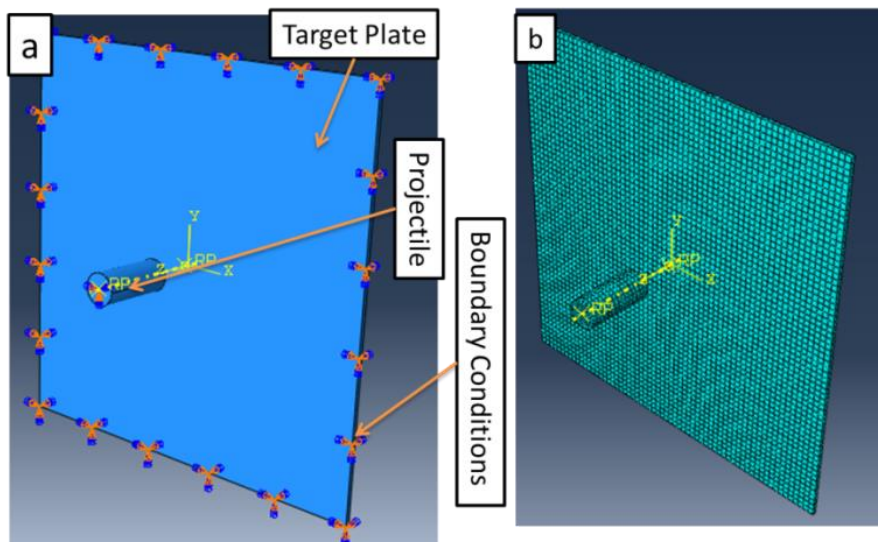

Figure 1. (a) Composite target plate with projectile assembly (b) Meshed composite plate and projectile

\section{BALLISTIC IMPACT ANALYSIS}

The ballistic impact is dealt with hitting the target by projectiles/bullets/missile and observe their effects on the deformation of the hitting surface. It is essential to model and understand the impact on the target/surface. Because, fabrication of composite materials and experimental testing involves more money, time and workforce and very tedious. The phenomenon of ballistic impact depends on variables such as the projectile (size/shape, mass, and velocity) and target (thickness, material, and properties of the material) for the analysis.

The energy absorbed by the composite target material is calculated using the Eq. (1) and Eq. (2) [16-17].

$$
\begin{gathered}
E_{a}=0.5 m_{p}\left(v_{i}^{2}-v_{r}^{2}\right) \\
v_{b}=\sqrt{\left(v_{i}^{2}-v_{r}^{2}\right)}
\end{gathered}
$$

where,
$\mathrm{E}_{\mathrm{a}}=$ Energy absorbed by target $(\mathrm{J})$

$\mathrm{m}_{\mathrm{p}}=$ Mass of the projectile $(\mathrm{kg})$

$\mathrm{V}_{\mathrm{i}}=$ Impact velocity or input or initial velocity $\left(\mathrm{ms}^{-1}\right)$

$\mathrm{V}_{\mathrm{r}}=$ Residual velocity $\left(\mathrm{ms}^{-1}\right)$

$\mathrm{V}_{\mathrm{b}}=$ Ballistic limit velocity $\left(\mathrm{ms}^{-1}\right)$

\section{RESULTS AND DISCUSSIONS}

The effect of the interlayers laminate material on the ballistic ability of composite plate was examined from the FE simulation. The presence of the intermediate layer changed the stress-waves propagation among the layers. Natural rubber interlayer plays a significant role in delaying and reduction in the amount of stress transmitted [11] to the GE composite backing plate, which leads to the high energy absorption in GREC sandwich. The projectile, hitting the laminate before and target plate is shown in Figure 2(a). Damage of NR was highly elastoplastic in nature with stress contraction, and relaxation is shown in Figure 2(c). Damage in the GE laminate was highly brittle on removing the material around the projectile impact shown in Figure 2(b). Whereas NR interlayer sandwich extent the damage region in the radial direction which leads to more area of damage towards the opposite side of the projectile penetration is appeared in Figure 2 (d).
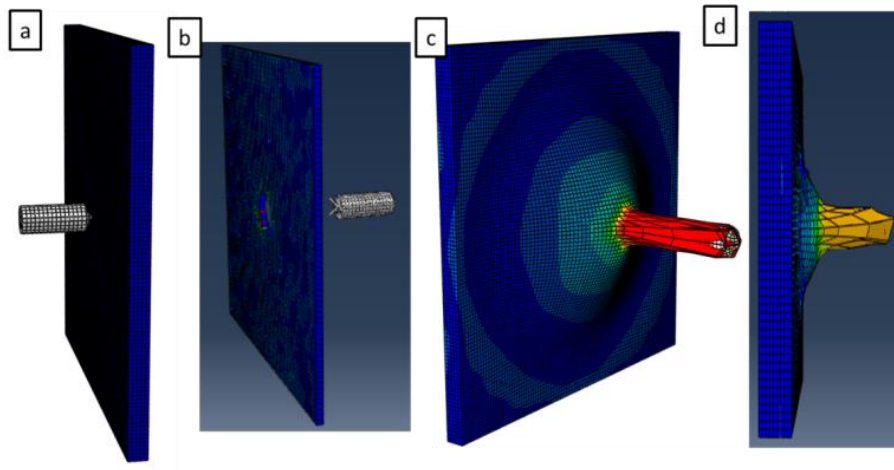

Figure 2. (a)Projectile before impact (b) Damage of GE composite (c) Natural rubber (d) GREC sandwich plate impacted with a conical projectile at $350 \mathrm{~m} / \mathrm{s}$ velocity

The initial and residual velocity of the projectile data is obtained from the simulation by considering rigid bullet (no mass loss, no deformation, and no fragmentation of projectile). The energy absorbed and ballistic limits are calculated using Eq. (1) and Eq. (2) respectively. The GEC plate has increased its energy absorption, and ballistic limit as the thickness and impact velocity increases is shown in Figure 3(a) and (b). It is noticed that $10 \mathrm{~mm}$ thick laminate impacted at the highest velocity $(260 \mathrm{~m} / \mathrm{s})$ whereas $4 \mathrm{~mm}$ thick GEC laminate impacted with lower velocity $(180 \mathrm{~m} / \mathrm{s})$. The thickness of GEC increased from $4 \mathrm{~mm}$ to $10 \mathrm{~mm}$; there is a $38 \%$ increase in the energy absorption and $28 \%$ enhancement of ballistic limit.

Increase in energy absorbed is noticed in natural rubber composite plates for higher impact velocity. Figure 4(a) and 4(b) show the different laminated plate energy absorbance and ballistic impact with different velocity. It is perceived that GREC sandwich is higher absorbance and ballistic limit than the NR and GEC laminate. In the same observation, NR laminate is marginally lower than the GREC plate. 


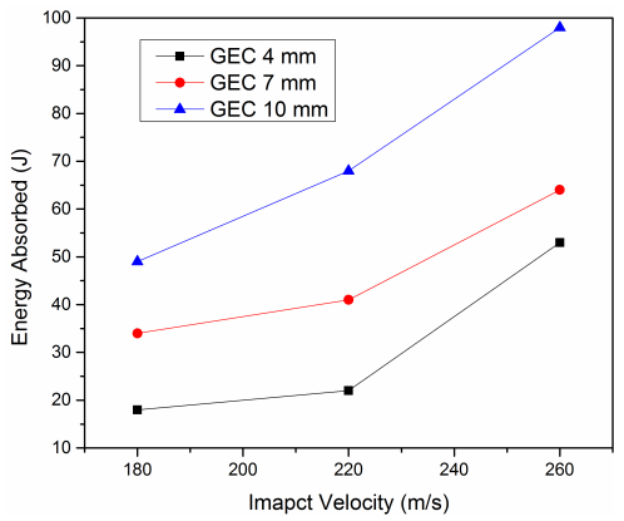

(a)

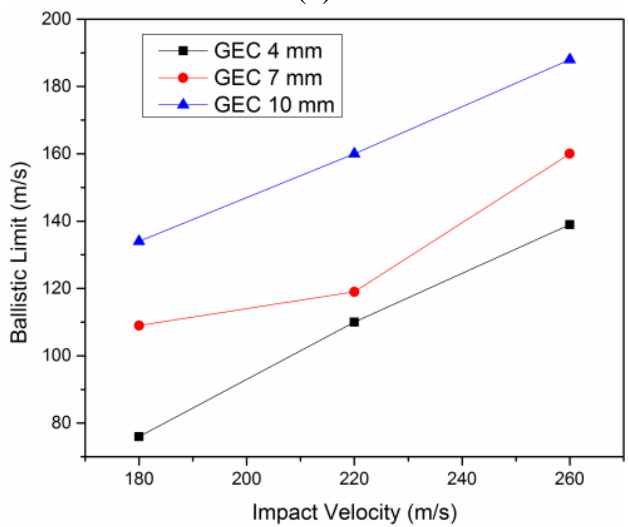

(b)

Figure 3. (a) Energy absorption of GE composite (b) ballistic limit GE composite target for different impact velocity and thicknesses

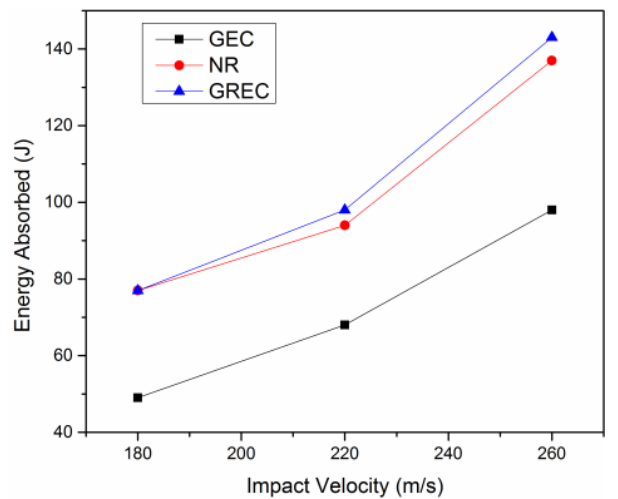

(a)

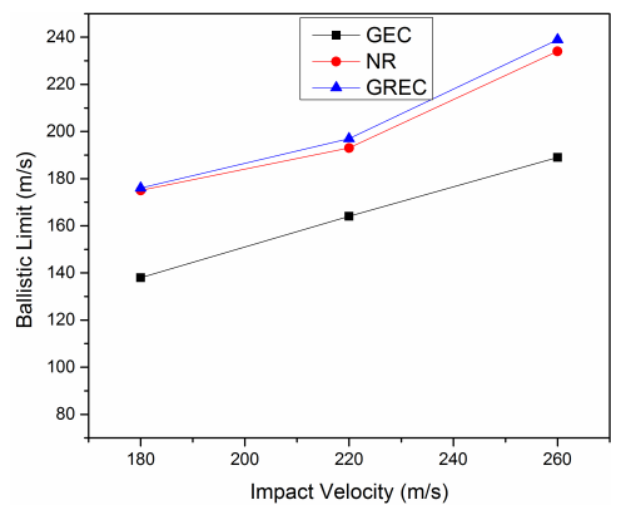

(b)

Figure 4. (a) Energy absorption (b) Ballistic limit of NR, GE and GRE target plates for different impact velocity for $10 \mathrm{~mm}$ thick plate

\section{CONCLUSIONS}

In summary, the following conclusions were drawn from the ballistic impact analysis of the composite. As the thickness of the NR increased from $4 \mathrm{~mm}$ to $10 \mathrm{~mm}$, the energy absorption also increased by $38 \%$, Whereas for GEC, there is an improvement of $54 \%$.

The ballistic limit and absorbed energy increase with the increase in the thickness of the laminates for NR and GEC. Energy absorption of sandwich composite (GREC) was $22 \%$ higher than GEC and $4 \%$ higher than NR.

The energy absorbed and ballistic limit of the GREC and NR laminates are found to be almost near and quite higher than GEC. Compliance nature of the damage was obtained for NR, Whereas, in the case of GEC brittle damage occurs. Finally, GREC sandwich failed by mixed mode brittle fracture followed by deformation and de-bonding

The finding of these results is used for the experimental validation study. Also, these composites may serve in highvelocity protection and bulletproof application.

\section{ACKNOWLEDGMENT}

The author's thanks to the Department of Metallurgical and Materials Engineering and Department of Mechanical Engineering, NIT, Karnataka for providing computation facility.

\section{REFERENCES}

[1] Pawar, M.J., Patnaik, A., Nagar, R. (2016). Numerical simulation and experimental validation of granite powder filled jute epoxy composite for slurry jet erosive wear. International Polymer Processing, 31(1): 37-50. https://doi.org/10.3139/217.3135

[2] Kumar, S., Gupta, D.S., Singh, I., Sharma, A. (2010). Behavior of kevlar/epoxy composite plates under ballistic impact. Journal of Reinforced Plastics and Composites, 29(13): 2048-2064. https://doi.org/10.1177/0731684409343727

[3] Sangamesh, R., Ravishankar, K.S., Kulkarni, S.M. (2018). Impact analysis of natural fiber and synthetic fiber reinforced polymer composite. In AIP Conference Proceedings, 1953(1): 130003. AIP Publishing. https://doi.org/10.1063/1.5033147

[4] Bunsell, A.R., Ramirez, J.M.H., Le Clerc, C. (2018). Tensile fatigue of thermoplastic fibers. In Handbook of Properties of Textile and Technical Fibres, Woodhead Publishing, pp. 595-618. https://doi.org/10.1016/B9780-08-101272-7.00016-X

[5] Guoqi, Z., Goldsmith, W., Dharan, C.H. (1992). Penetration of laminated Kevlar by projectiles-I. Experimental investigation. International Journal of Solids and Structures, 29(4): 399-420. https://doi.org/10.1016/0020-7683(92)90207-A

[6] Sikarwar, R.S., Velmurugan, R., Madhu, V. (2012). Experimental and analytical study of high velocity impact on Kevlar/Epoxy composite plates. Central European Journal of Engineering, 2(4): 638-649. https://doi.org/10.2478/s13531-012-0029-X

[7] Zahid, B., Chen, X. (2013). Impact evaluation of Kevlarbased angle-interlock woven textile composite structures. 
Journal of Reinforced Plastics and Composites, 32(12): 925-932. https://doi.org/10.1177/0731684413480006

[8] Roy, T., Chakraborty, D. (2006). Delamination in hybrid FRP laminates under low velocity impact. Journal of Reinforced Plastics and Composites, 25(18): 1939-1956. https://doi.org/10.1177/0731684406069922

[9] Pasha, R.A., Khan, H.H., Nasir, M.A., Anjum, N.A., Sardar, H.W. (2018). Effect of Rubber particles on kevlar fiber reinforced polymer composite against high velocity impact. Technical Journal, 23(01): 35-41.

[10] Sevkat, E., Liaw, B., Delale, F., Raju, B.B. (2009). A combined experimental and numerical approach to study ballistic impact response of S2-glass fiber/toughened epoxy composite beams. Composites Science and Technology, 69(7-8): 965-982. https://doi.org/10.1016/j.compscitech.2009.01.001

[11] Gama, B.A., Bogetti, T.A., Fink, B.K., Yu, C.J., Claar, T.D., Eifert, H.H., Gillespie Jr, J.W. (2001). Aluminum foam integral armor: a new dimension in armor design. Composite Structures, 52(3-4): 381-395. https://doi.org/10.1016/S0263-8223(01)00029-0

[12] Agarwal, K., Setua, D.K., Mathur, G.N. (2002). Short fibre and particulate-reinforced rubber composites. Defence Science Journal, 52(3): 337-346. https://doi.org/10.14429/dsj.52.2189
[13] Ahmad, M.R., Ahmad, W.Y.W., Salleh, J., Samsuri, A. (2007). Performance of natural rubber coated fabrics under ballistic impact. Malaysian Polymer Journal, 2(1): 39-51.

[14] Tasdemirci, A., Tunusoglu, G., Güden, M. (2012). The effect of the interlayer on the ballistic performance of ceramic/composite armors: Experimental and numerical study. International Journal of Impact Engineering, 44: $1-9$. https://doi.org/10.1016/j.ijimpeng.2011.12.005

[15] Velmurugan, R., Sikarwar, R.S. (2014). Ballistic impact on glass/epoxy composite laminates. Defence Science Journal, 64(4): 393-399. https://doi.org/10.14429/dsj.64.3882

[16] Ravishankar, K.S., Kulkarni, S.M. (2018). Ballistic impact study on jute-epoxy and natural rubber sandwich composites. Materials Today: Proceedings, 5(2): 69166923. https://doi.org/10.1016/j.matpr.2017.11.353

[17] Ramadhan, A.A., Talib, A.A., Rafie, A.M., Zahari, R. (2013). High velocity impact response of Kevlar29/epoxy and 6061-T6 aluminum laminated panels. Materials \& Design, 43: 307-321. https://doi.org/10.1016/j.matdes.2012.06.034 